\title{
Article \\ Prevalence of Drug-Resistant Tuberculosis in Sudan: A Systematic Review and Meta-Analysis
}

\author{
Khalid Hajissa ${ }^{1,2}$, Mahfuza Marzan ${ }^{3}$, Mubarak Ibrahim Idriss ${ }^{4}\left(\mathbb{D}\right.$ and Md Asiful Islam ${ }^{5, *(\mathbb{D}}$ \\ 1 Department of Medical Microbiology \& Parasitology, School of Medical Sciences, Universiti Sains Malaysia, \\ Kubang Kerian 16150, Kelantan, Malaysia; khalidhaj@usm.my \\ 2 Department of Zoology, Faculty of Science and Technology, Omdurman Islamic University, P.O. Box 382, \\ Omdurman 14415, Sudan \\ 3 Department of Microbiology, Jahangirnagar University, Savar, Dhaka 1342, Bangladesh; mmarzan@juniv.edu \\ 4 Laboratory Division, Kassala State Ministry of Health, Kassala, Sudan; mubarak.mareh@yahoo.com \\ 5 Department of Haematology, School of Medical Sciences, Universiti Sains Malaysia, \\ Kubang Kerian 16150, Kelantan, Malaysia \\ * Correspondence: asiful@usm.my or ayoncx70@yahoo.com
}

check for updates

Citation: Hajissa, K.; Marzan, M.; Idriss, M.I.; Islam, M.A. Prevalence of Drug-Resistant Tuberculosis in Sudan: A Systematic Review and Meta-Analysis. Antibiotics 2021, 10, 932. https://doi.org/

10.3390/antibiotics10080932

Academic Editor: Mario C Raviglione

Received: 21 June 2021

Accepted: 30 July 2021

Published: 31 July 2021

Publisher's Note: MDPI stays neutral with regard to jurisdictional claims in published maps and institutional affiliations.

Copyright: (c) 2021 by the authors. Licensee MDPI, Basel, Switzerland. This article is an open access article distributed under the terms and conditions of the Creative Commons Attribution (CC BY) license (https:// creativecommons.org/licenses/by/ $4.0 /)$.
Abstract: Drug-resistant tuberculosis (DR-TB) is still one of the most critical issues impeding worldwide TB control efforts. The aim of this systematic review and meta-analysis was to give an updated picture of the prevalence of DR-TB in Sudan. A comprehensive systematic search was performed on four electronic databases (PubMed, Scopus, Web of Science and Google Scholar) to identify all published studies reporting prevalence data of DR-TB in Sudan. Sixteen eligible studies published during 2002-2020 were included. Using meta-analysis of proportions, the pooled prevalence of TB cases with resistance to any anti-TB drugs was $47.0 \%$ (95\% CI: 35.5-58.6\%). The overall prevalence of mono, multi, poly and extensive drug resistance were estimated to be $16.2 \%$ (95\% CI: 9.0-23.4\%), $22.8 \%$ (95\% CI: 16.0-29.7\%), 6.8\% (95\% CI: 0.5-13.0\%) and 0.7\% (95\% CI: 0-2.1\%), respectively. Considering any first-line anti-TB drugs, the resistance prevalence was highest for isoniazid (32.3\%) and streptomycin $(31.7 \%)$, followed by rifampicin (29.2\%). In contrast, resistance against second-line drugs was reported for only two antibiotics, namely, ofloxacin $(2.1 \%)$ and kanamycin $(0.7 \%)$. Of note, the resistance profile of the previously treated patients was found to be remarkably high compared with the newly diagnosed TB patients. The relatively high prevalence estimation of anti-TB drug resistance warrants strengthening TB control and treatment strategies in Sudan.

Keywords: tuberculosis; antibiotic resistance; drug-resistant; prevalence; epidemiology; Sudan; systematic review; meta-analysis

\section{Introduction}

Despite the improvements in case identification, cure rates and implementation of a widely adopted control strategy, tuberculosis (TB) remains a significant health threat and continues to be one of the top infectious and fatal diseases [1,2]. The global TB statistics revealed 10 million infected individuals and approximately 1.4 million deaths in 2019 worldwide [3]. The disease geographic distribution disproportionately varies within countries and across the globe, and poverty is the strongest predictor of incidence [4,5]. In Africa, where inadequate diagnosis and treatment are extremely common, the incidence rate of the disease is particularly high and accounts for $25 \%$ of the global TB cases [6]. Sudan is among the developing countries where TB is a major public health challenge, with an estimated 29,000 cases in 2019 [3].

The prevention of new TB infections and effective treatment of established ones are critical to achieving remarkable reductions in the burden of the disease and associated deaths [7]. Globally, the successful treatment rate among TB-confirmed, -reported and -treated cases in 2018 was 85\% [1]. However, the inadequate treatment of TB-infected patients enables bacterial strains to develop several resistance strategies against antimicrobial 
agents despite effectively killing the majority of the invaded bacteria [8]. Current efforts for accelerated TB control are challenged by the emergence of antibiotic resistance resulting in drug-resistant tuberculosis (DR-TB) [9]. The World Health Organisation (WHO) estimated that 465,000 of TB cases in 2019 had rifampicin resistance, of which $78 \%$ were further confirmed as multidrug-resistant TB (MDR-TB), having TB strains resistant to rifampicin and isoniazid [3]. Proper combinations of first- and second-line TB drugs have been effectively used in treating patients with MDR-TB, but the emergence of extensively drug-resistant tuberculosis (XDR-TB), which was defined as MDR-TB with resistance to fluoroquinolone, and at least one of the injectable second-line drug, has caused recent concern [9-11]. The increasing incidence of MDR-TB and XDR-TB in many parts of the world further threatens $\mathrm{TB}$ control efforts due to the high risk of treatment failure and death.

TB drug-resistance patterns in a country always reflect the effectiveness of its current and prior TB control programs. Therefore, regular surveillance of TB drug resistance is central to combating the global burden of $\mathrm{TB}$ and preventing the wide spread of antimicrobial resistance [12]. However, performing surveillance in most of the African countries is often limited by a lack of resources. This situation is reflected by the absence or insufficient data on anti-TB drug resistance [13]. Therefore, urgent efforts are needed to determine the true burden of DR-TB throughout Africa [14]. In Sudan, the rate of DR-TB has been reported in several published studies; however, most of these reports presented local information or region-specific data, and no study has systematically evaluated DR-TB prevalence data in Sudan. Therefore, this systematic review and meta-analysis (SRMA) was conducted to provide an updated and comprehensive assessment of the burden of DR-TB in Sudan.

\section{Results}

\subsection{Study Selection}

A flow diagram shows the results of the literature search, and the study selection process is presented in Figure 1. A total of 599 potentially relevant articles were initially identified in the systematic literature search, of which 199 were duplicates, 337 were excluded based on the review of their titles and abstracts, and 63 articles were retained for assessment. After full-text evaluation, only 16 articles addressing the prevalence of drug-resistant TB were included in this SRMA.

\subsection{Characteristics of the Included Studies}

The detailed characteristics of the 16 included studies are summarised in Table 1. The 16 included studies had cross-sectional designs. A total of 1786 Sudanese TB patients were identified and subjected to drug susceptibility testing. The mean age of the patients had a range of 5-90 years. Of the 16 articles, 13 provided data on any drug-resistant TB, 15 provided data on MDR, 13 provided data on isoniazid and 14 on rifampicin, 7 contained information on new TB cases and 8 provided data on previously treated cases. 


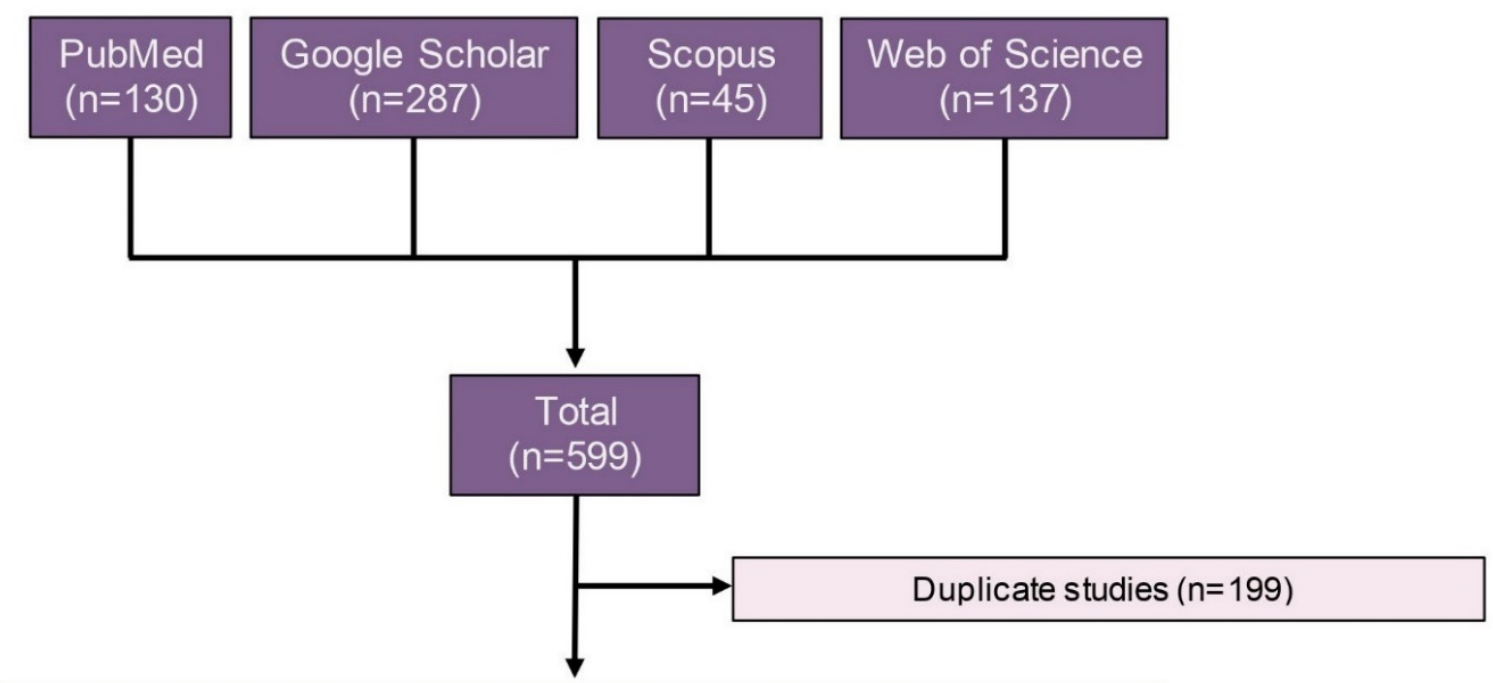

\section{0 studies were selected for title and abstract screening}

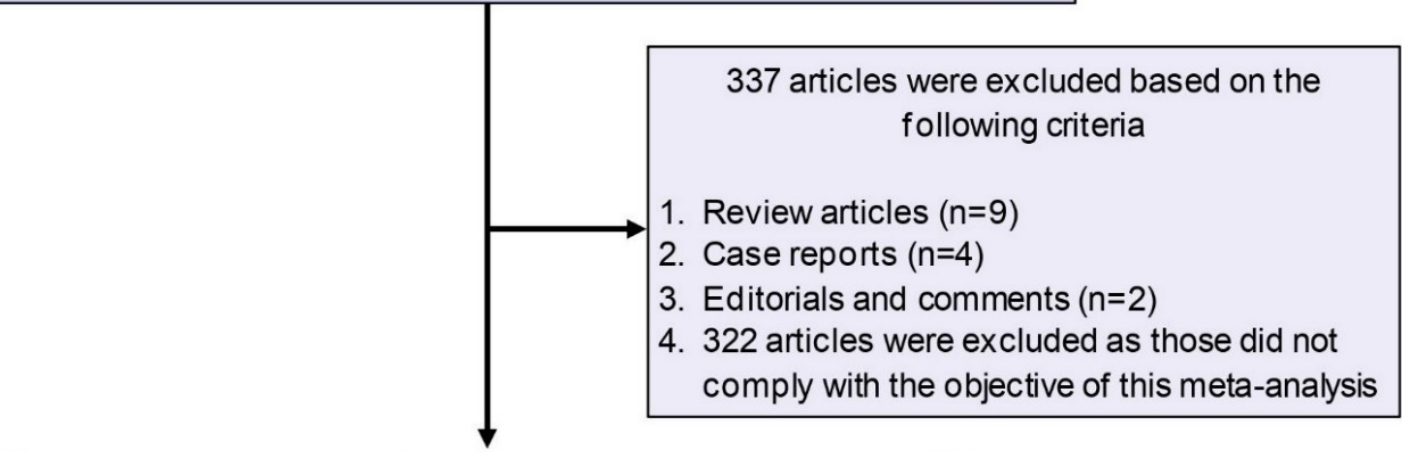

63 studies were selected for full text screening

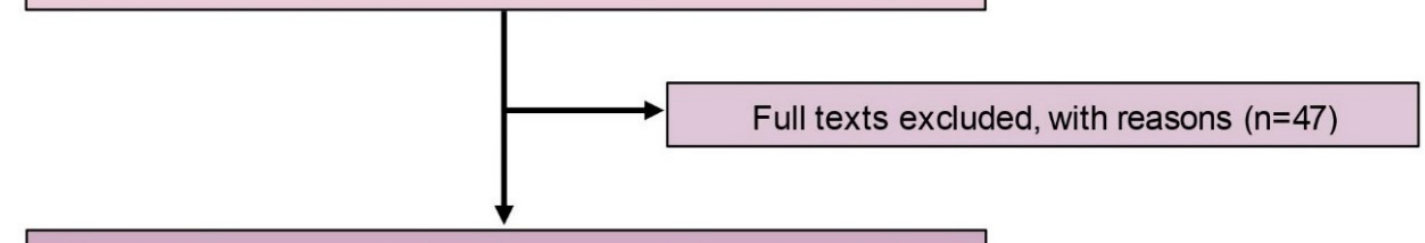

16 studies were selected for quantitative evaluation

16 studies were selected for the meta-analysis

Figure 1. PRISMA flow diagram of study selection. 
Table 1. Major characteristics of the included studies.

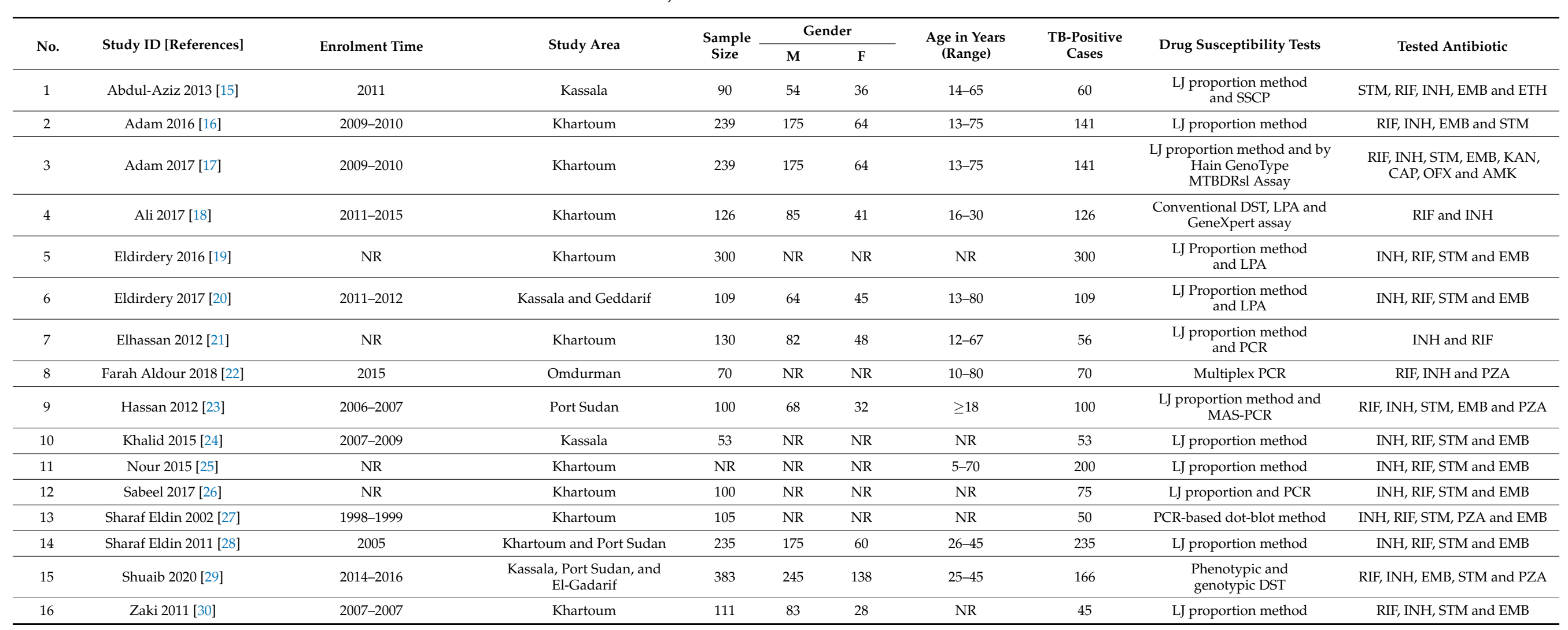

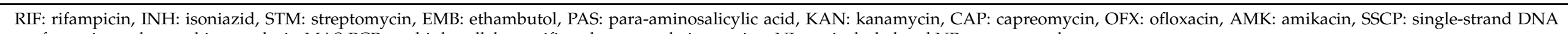
conformation polymorphism analysis, MAS-PCR: multiplex allele specific polymerase chain reaction, NI: not included and NR: not reported. 


\subsection{Quality Assessment and Publication Bias}

Quality assessment of the included studies using the JBI critical appraisal checklist for cross-sectional studies is shown in Table S1. Briefly, 11 (68.7\%) studies were assessed as having a low risk of bias (high quality), whereas the remaining $5(31.3 \%)$ studies were assessed as having a moderate risk of bias. Assessment of publication bias with funnel plots was possible only in two analyses. Symmetrical and asymmetrical funnel plots (Figure 2) indicated the absence and existence of publication bias, respectively, which were statistically verified through Egger's test $(p=0.41$ and $<0.0001)$.

A

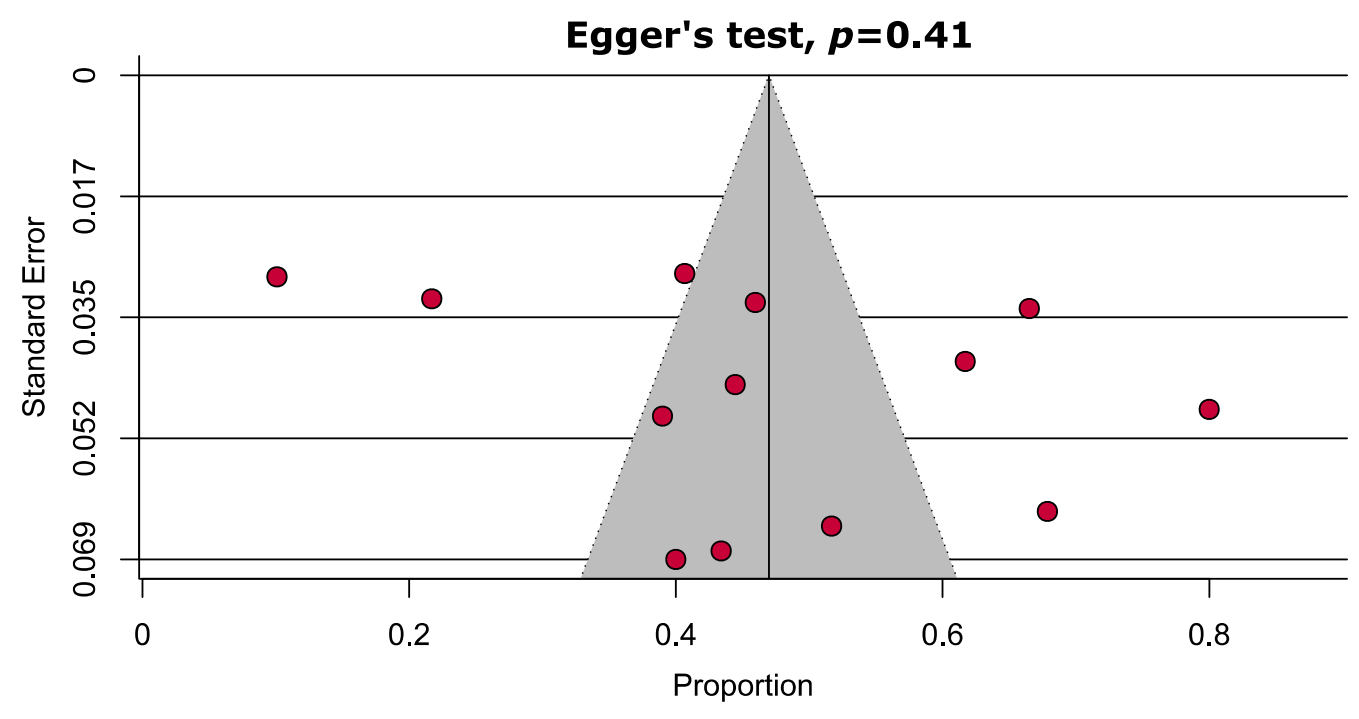

B

Egger's test, $p<0.0001$

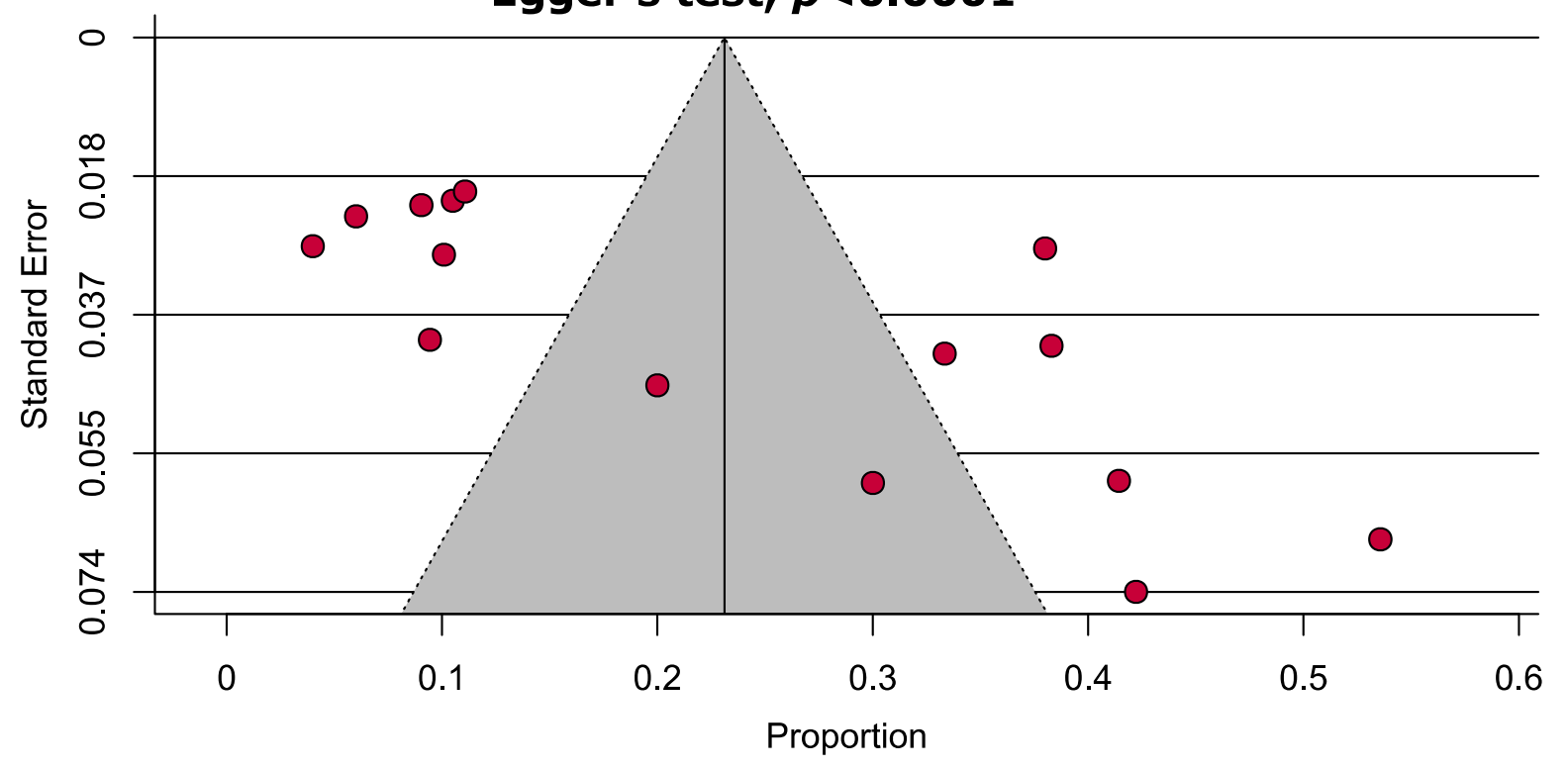

Figure 2. Funnel plots analysing publication bias among studies evaluated (A) any drug resistance and (B) multidrug resistance. 


\subsection{Overall Antibiotic Resistance Patterns}

Figure 3 shows the overall antibiotic resistance prevalence in the positive cases of $\mathrm{TB}$ in Sudan. The meta-analysis revealed that $47.0 \%$ (95\% CI: 35.5\%-58.6\%) of all TB cases had resistance to at least one of the tested anti-TB drugs (resistance to any drug). The overall prevalence of mono-resistant TB was 16.2\% (95\% CI: 9.0\%-23.4\%), multi drug-resistant TB had $22.8 \%$ (95\% CI: $16.0 \%-29.7 \%$ ) and poly-resistant TB had 6.8\% (95\% CI: $0.5 \%-13.0 \%)$. Only one XDR isolate was identified, with an estimated prevalence of $0.7 \%$ (95\% CI: $0 \%-2.1 \%$ ).

A

\section{Study ID \\ Any drug-resistance}

Abdul-Aziz 2013

Adam 2016

Ali 2017

Eldirdery 2016

Eldirdery 2017

Elhassan 2012

Farah Aldour 2018

Hassan 2012

Khalid 2015

Nour 2015

Sharaf Eldin 2002

Sharaf Eldin 2011

Shuaib 2020
Cases Total Prevalence $\quad 95 \%$ C.I.

$\begin{array}{rr}31 & 60 \\ 87 & 141 \\ 56 & 126 \\ 122 & 300 \\ 11 & 109 \\ 38 & 56 \\ 56 & 70 \\ 39 & 100 \\ 23 & 53 \\ 133 & 200 \\ 20 & 50 \\ 108 & 235 \\ 36 & 166\end{array}$

$51.7[39.0 ; 64.3]$

$61.7[53.7 ; 69.7]$

$44.4[35.8 ; 53.1]$

$40.7[35.1 ; 46.2]$

$10.1 \quad[4.4 ; 15.7]$

$67.9[55.6 ; 80.1]$

$80.0[70.6 ; 89.4]$

$39.0[29.4 ; 48.6]$

$43.4[30.1 ; 56.7]$

$66.5[60.0 ; 73.0]$

$40.0[26.4 ; 53.6]$

$46.0[39.6 ; 52.3]$

$21.7[15.4 ; 28.0]$

$47.0[35.5 ; 58.6]$

1666

Random effects model

Heterogeneity: $I^{2}=96 \%, \tau^{2}=0.0428, \chi_{12}^{2}=324.67(p<0.01)$
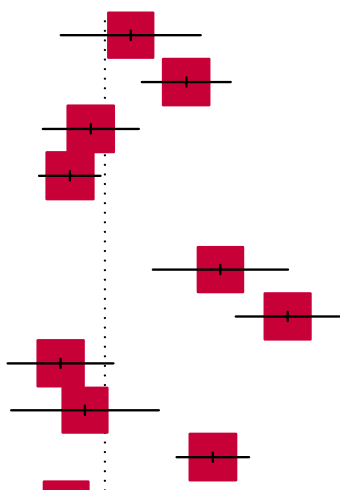

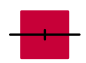

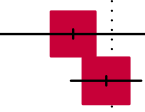

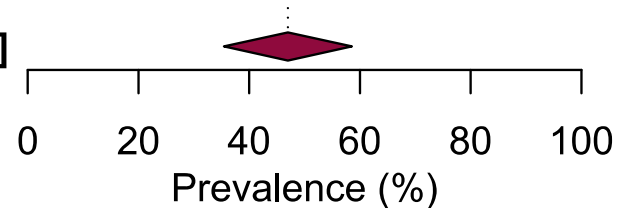

B

Study ID Mono drug-resistance

Abdul-Aziz 2013

Adam 2016

Ali 2017

Eldirdery 2016

Elhassan 2012

Farah Aldour 2018

Hassan 2012

Sharaf Eldin 2002

\section{Cases Total Prevalence $\quad 95 \%$ C.I.}

$20.0 \quad[9.9 ; 30.1]$

$17.0[10.8 ; 23.2]$

$11.1[5.6 ; 16.6]$

$2.7 \quad[0.8 ; 4.5]$

$14.3[5.1 ; 23.5]$

$22.9[13.0 ; 32.7]$

$22.0[13.9 ; 30.1]$

$24.0[12.2 ; 35.8]$

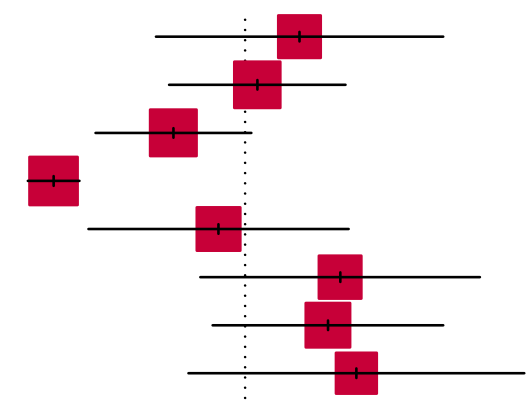

$16.2[9.0 ; 23.4]$

903

Random effects model

Heterogeneity: $I^{2}=90 \%, \tau^{2}=0.0091, \chi_{7}^{2}=73.36(p<0.01)$

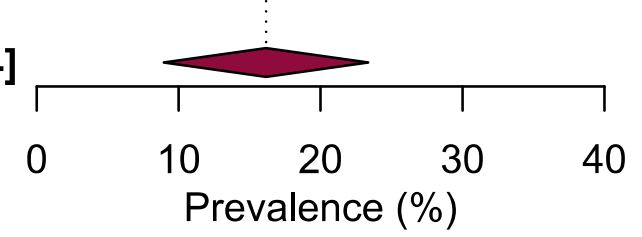


C

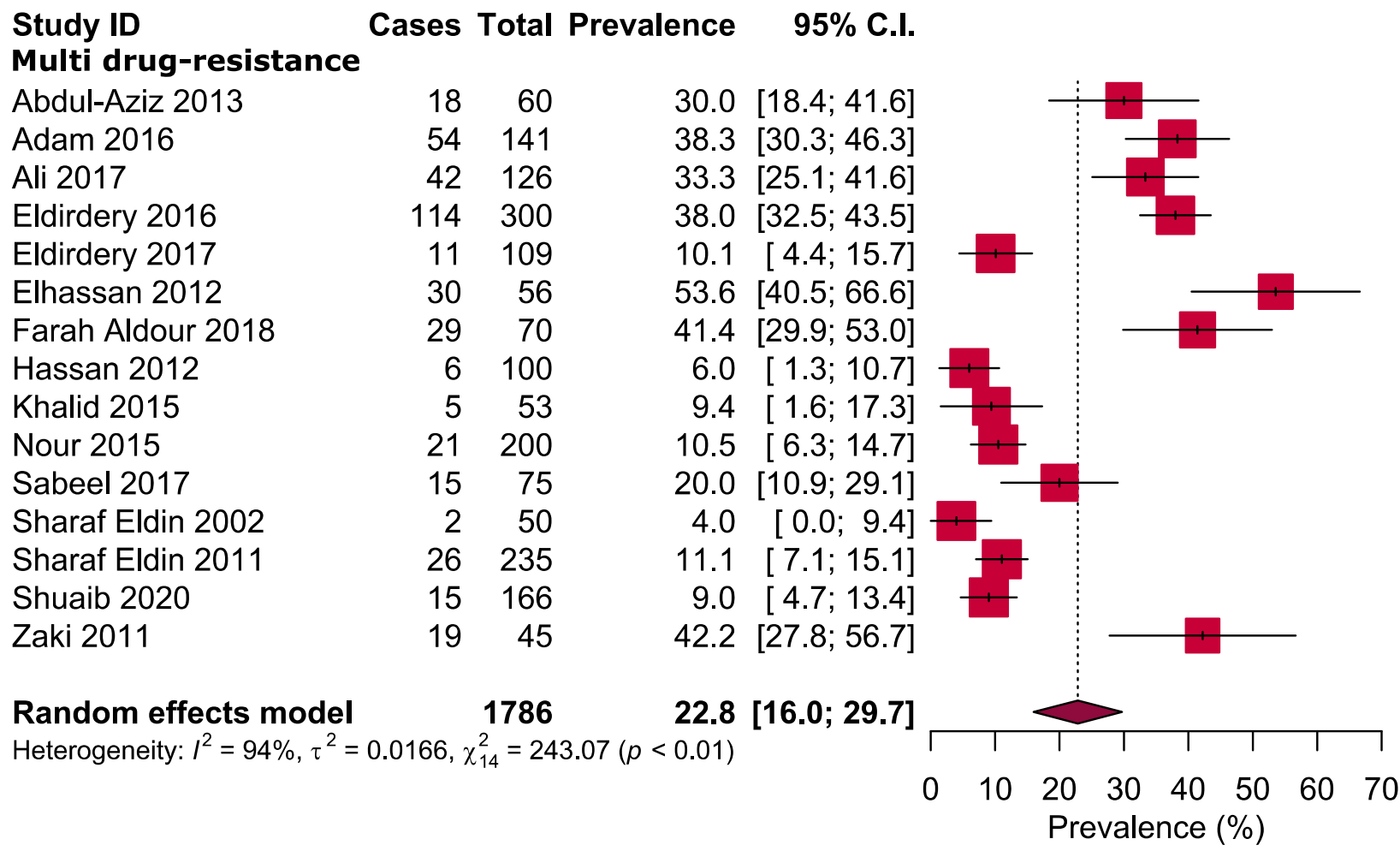

D

Study ID

Poly drug-resistance

Abdul-Aziz 2013

Adam 2016

Farah Aldour 2018

Random effects model

Heterogeneity: $I^{2}=81 \%, \tau^{2}=0.0023, \chi_{2}^{2}=10.42(p<0.01)$

$\begin{array}{rr}1 & 60 \\ 9 & 141 \\ 11 & 70\end{array}$

Cases Total Prevalence $95 \%$ C.I.

$1.7 \quad[0.0 ; 4.9]$

$6.4[2.3 ; 10.4]$

$15.7[7.2 ; 24.2]$

$6.8[0.5 ; 13.0]$

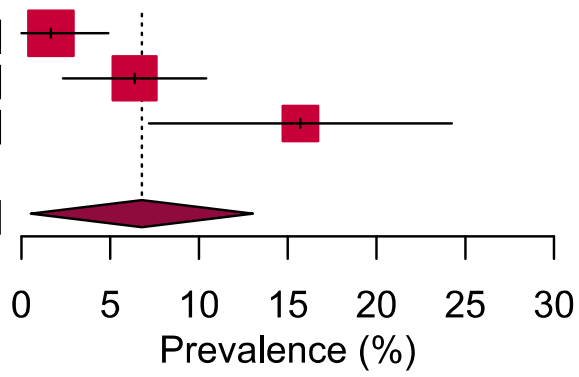

E

Study ID Cases Total Prevalence 95\% C.I. Extensive drug-resistance

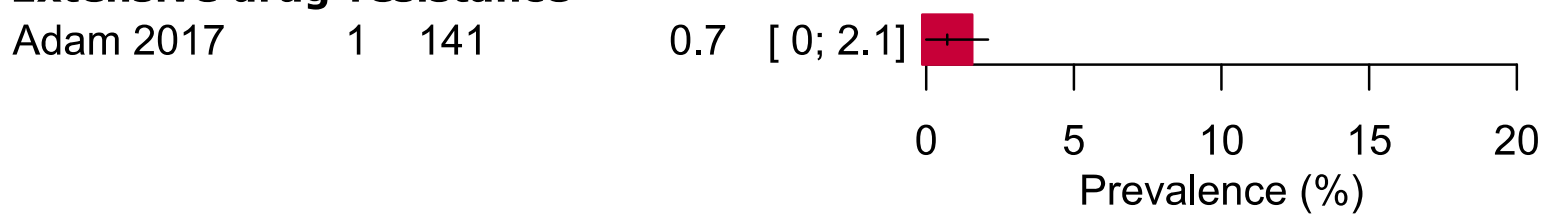

Figure 3. Prevalence of (A) any drug resistance, $(\mathbf{B})$ mono drug resistance, $(\mathbf{C})$ multidrug resistance, (D) poly drug resistance and (E) extensive drug resistance in pulmonary tuberculosis in Sudan. 


\subsection{Resistance to First-Line Anti-TB Drugs}

The results of the drug susceptibility tests for any of the five reported first-line anti-TB drugs are detailed in Table 2 and Figure S1. Resistance to isoniazid was the most common, detected in $32.3 \%$ (95\% CI: $23.6-41.1 \%$ ) of the resistant strains, followed by resistance to streptomycin (31.7\%; 95\% CI: 24.6-38.8\%). The proportion of patients with rifampicin, ethambutol and pyrazinamide resistance were $29.2 \%, 15.7 \%$ and $10.5 \%$, respectively. In addition, mono resistance for streptomycin $(14.0 \%)$, isoniazid $(2.8 \%)$, rifampicin $(0.7 \%)$, and ethambutol (2.1\%) was found (Table 2 and Figure S2).

Table 2. Any and mono anti-tuberculosis DR patterns in Sudan.

\begin{tabular}{|c|c|c|c|c|c|c|c|}
\hline \multirow{2}{*}{\multicolumn{2}{|c|}{ Drug-Resistance Patterns }} & \multirow{2}{*}{ Antibiotics } & \multirow{2}{*}{$\begin{array}{l}\text { Number of } \\
\text { Analysed } \\
\text { Studies }\end{array}$} & \multirow{2}{*}{$\begin{array}{c}\text { Total Number } \\
\text { of } \\
\text { Tuberculosis } \\
\text { Patients }\end{array}$} & \multirow{2}{*}{$\begin{array}{c}\text { Prevalence of } \\
\text { Antibiotic } \\
\text { Resistance } \\
{[95 \% \text { CIs] (\%) }}\end{array}$} & \multicolumn{2}{|c|}{ Heterogeneity } \\
\hline & & & & & & $I^{2}$ & $p$-Value \\
\hline \multirow{7}{*}{ Any DR } & \multirow{5}{*}{$\begin{array}{l}\text { First-line } \\
\text { drugs }\end{array}$} & Streptomycin & 10 & 1125 & 31.7 [24.6-38.8] & $86 \%$ & $<0.0001$ \\
\hline & & Isoniazid & 13 & 1624 & $32.3[23.6-41.1]$ & $94 \%$ & $<0.0001$ \\
\hline & & Rifampicin & 14 & 1677 & 29.2 [21.4-36.9] & $94 \%$ & $<0.0001$ \\
\hline & & Ethambutol & 9 & 1072 & $15.7[8.0-23.4]$ & $95 \%$ & $<0.0001$ \\
\hline & & Pyrazinamide & 3 & 336 & $10.5[2.8-18.1]$ & $97 \%$ & $<0.0001$ \\
\hline & \multirow{2}{*}{$\begin{array}{l}\text { Second-line } \\
\text { drugs }\end{array}$} & Kanamycin & 1 & 141 & $0.7[0.0-2.1]$ & NA & NA \\
\hline & & Ofloxacin & 1 & 141 & $2.1[0.0-4.5]$ & NA & NA \\
\hline \multirow{4}{*}{ Mono DR } & \multirow{4}{*}{$\begin{array}{l}\text { First-line } \\
\text { drugs }\end{array}$} & Streptomycin & 4 & 351 & $14.0[9.9-18.1]$ & $20 \%$ & 0.29 \\
\hline & & Isoniazid & 7 & 833 & $2.8[1.2-4.5]$ & $48 \%$ & 0.07 \\
\hline & & Rifampicin & 7 & 833 & $0.7[0.0-1.5]$ & $16 \%$ & 0.38 \\
\hline & & Ethambutol & 3 & 301 & $2.1[0.5-3.7]$ & $0 \%$ & 0.40 \\
\hline
\end{tabular}

CI: confidence interval; DR: drug resistance; NA: not applicable.

\subsection{Resistance to Second-Line Anti-TB Drugs}

The resistance profiles of the second-line drug were only reported for two antibiotics, namely ofloxacin and kanamycin, and the corresponding pooled prevalence was estimated. Resistance prevalence to ofloxacin $(2.1 \%, 95 \%$ CI: $0-4.5 \%)$ and kanamycin $(0.7 \%, 95 \%$ CI: $0-2.1 \%)$ were notably low (Table 2 and Figure S1).

\subsection{Drug-Resistance Pattern Based on Treatment History}

The patterns of DR-TB according to treatment status (new or previously treated cases) are shown in Table 3. The meta-analysis result revealed that $30.7 \%$ and $62.8 \%$ of newly diagnosed and previously treated TB patients were resistant to at least one drug (Figures S3-S5). Mono-resistance, MDR and poly-resistance rates were $21.2 \%, 11.4 \%$ and $2.2 \%$, respectively, for the new TB cases and $18.8 \%, 41.5 \%$ and $7.3 \%$, respectively, for the re-treatment cases (Figures S3-S5). Concerning the first-line drugs, resistance was remarkably high among the previously treated patients compared with that among the new cases. Resistance to streptomycin was the most common, with rates of $22.1 \%$ (newly treated cases) and $51.1 \%$ (re-treatment cases; Table 3 and Figures S3 and S4). Rates of resistance to isoniazid (42.8\%) and rifampicin $(39.3 \%)$ were notably high among re-treatment cases but low in newly diagnosed cases (Table 3 and Figure S4). Notably, resistance to second-line drugs was only reported among re-treatment cases. The prevalence of mono-resistance for first-line drugs ranged from $0.2 \%$ (rifampicin) to $13.5 \%$ (streptomycin) in new cases and from $1.4 \%$ (rifampicin) to $12.2 \%$ (streptomycin) for previously treated cases (Figures S4 and S5). 
Table 3. Anti-tuberculosis DR patterns in newly diagnosed and previously diagnosed tuberculosis patients from Sudan.

\begin{tabular}{|c|c|c|c|c|c|c|c|}
\hline \multirow{2}{*}{\multicolumn{2}{|c|}{$\begin{array}{l}\text { Drug-Resistance } \\
\text { Patterns }\end{array}$}} & \multirow{2}{*}{ Antibiotics } & \multirow{2}{*}{$\begin{array}{l}\text { Number of } \\
\text { Analysed } \\
\text { Studies }\end{array}$} & \multirow{2}{*}{$\begin{array}{l}\text { Total Number of } \\
\text { Tuberculosis } \\
\text { Patients }\end{array}$} & \multirow{2}{*}{$\begin{array}{c}\text { Prevalence of } \\
\text { Antibiotic } \\
\text { Resistance } \\
{[95 \% \text { CIs] (\%) }}\end{array}$} & \multicolumn{2}{|c|}{ Heterogeneity } \\
\hline & & & & & & $I^{2}$ & $p$-Value \\
\hline \multicolumn{8}{|c|}{ Newly diagnosed tuberculosis patients } \\
\hline \multirow{5}{*}{ Any DR } & \multirow{5}{*}{$\begin{array}{l}\text { First-line } \\
\text { drugs }\end{array}$} & Streptomycin & 4 & 321 & $22.1[10.7-33.6]$ & $80 \%$ & 0.001 \\
\hline & & Isoniazid & 3 & 310 & $15.7[7.3-24.1]$ & $74 \%$ & 0.02 \\
\hline & & Rifampicin & 4 & 321 & 14.8 [7.5-22.1] & $65 \%$ & 0.03 \\
\hline & & Ethambutol & 3 & 310 & $7.9[3.8-12.1]$ & $38 \%$ & 0.19 \\
\hline & & Pyrazinamide & 1 & 100 & $1.0[0.0-3.0]$ & NA & NA \\
\hline \multirow{4}{*}{ Mono DR } & \multirow{4}{*}{$\begin{array}{l}\text { First-line } \\
\text { drugs }\end{array}$} & Streptomycin & 2 & 146 & $13.5[4.4-22.6]$ & $63 \%$ & 0.10 \\
\hline & & Isoniazid & 2 & 146 & $1.5[0.0-3.8]$ & $11 \%$ & 0.29 \\
\hline & & Rifampicin & 2 & 146 & $0.2[0.0-1.5]$ & $0 \%$ & 0.45 \\
\hline & & Ethambutol & 2 & 146 & $3.3[0.4-6.2]$ & $0 \%$ & 0.69 \\
\hline \multicolumn{8}{|c|}{ Previously treated tuberculosis patients } \\
\hline \multirow{7}{*}{ Any DR } & \multirow{5}{*}{$\begin{array}{l}\text { First-line } \\
\text { drugs }\end{array}$} & Streptomycin & 3 & 226 & $51.1[26.1-76.1]$ & $92 \%$ & $<0.0001$ \\
\hline & & Isoniazid & 4 & 296 & $42.8[37.2-48.4]$ & $0 \%$ & 0.54 \\
\hline & & Rifampicin & 4 & 296 & $39.3[33.4-45.2]$ & $8 \%$ & 0.35 \\
\hline & & Ethambutol & 3 & 226 & $39.4[13.0-65.8]$ & $93 \%$ & $<0.0001$ \\
\hline & & Pyrazinamide & 1 & 70 & $47.1[35.4-58.8]$ & NA & NA \\
\hline & \multirow{2}{*}{$\begin{array}{l}\text { Second-line } \\
\text { drugs }\end{array}$} & Kanamycin & 1 & 141 & $0.7[0.0-2.1]$ & NA & NA \\
\hline & & Ofloxacin & 1 & 141 & $2.1[0.0-4.5]$ & NA & NA \\
\hline \multirow{4}{*}{ Mono DR } & \multirow{4}{*}{$\begin{array}{l}\text { First-line } \\
\text { drugs }\end{array}$} & Streptomycin & 2 & 155 & $12.2[7.1-17.4]$ & $0 \%$ & 0.81 \\
\hline & & Isoniazid & 2 & 155 & $2.0[0.0-4.3]$ & $0 \%$ & 0.80 \\
\hline & & Rifampicin & 2 & 155 & $1.4[0.0-3.4]$ & $0 \%$ & 0.68 \\
\hline & & Ethambutol & 2 & 155 & $1.5[0.0-3.5]$ & $0 \%$ & 0.41 \\
\hline
\end{tabular}

CI: confidence interval; DR: drug resistance; NA: not applicable.

\subsection{Time Trend of Anti-TB DR in Sudan}

The assessment of the trend in the prevalence of DR-TB in Sudan during an 18-year timeframe showed clear evidence of declining trend of any drug-resistant (from 50.9\% to $42.9 \%$ ) and mono-resistant TB (from $19.8 \%$ to $12.7 \%$ ). However, the comparative analysis of the nationwide prevalence of MDR-TB over the same period revealed a worsening trend (from $18.6 \%$ before 2016 to $26.9 \%$ in the next five years) (Figure 4 ).

\subsection{Sensitivity Analyses}

Sensitivity analyses for assessing overall TB antibiotic resistance rates by excluding small studies and studies with low and moderate quality, and by using a fixed-effects model, which showed marginal differences in the re-estimated overall prevalence, and rates ranging from $10.9 \%$ lower to $4.8 \%$ higher were excluded (Table 4 and Figure S6). Overall, no study has significantly influenced the overall pooled estimate of DR-TB, and thus, all the outcomes are robust and reliable. 


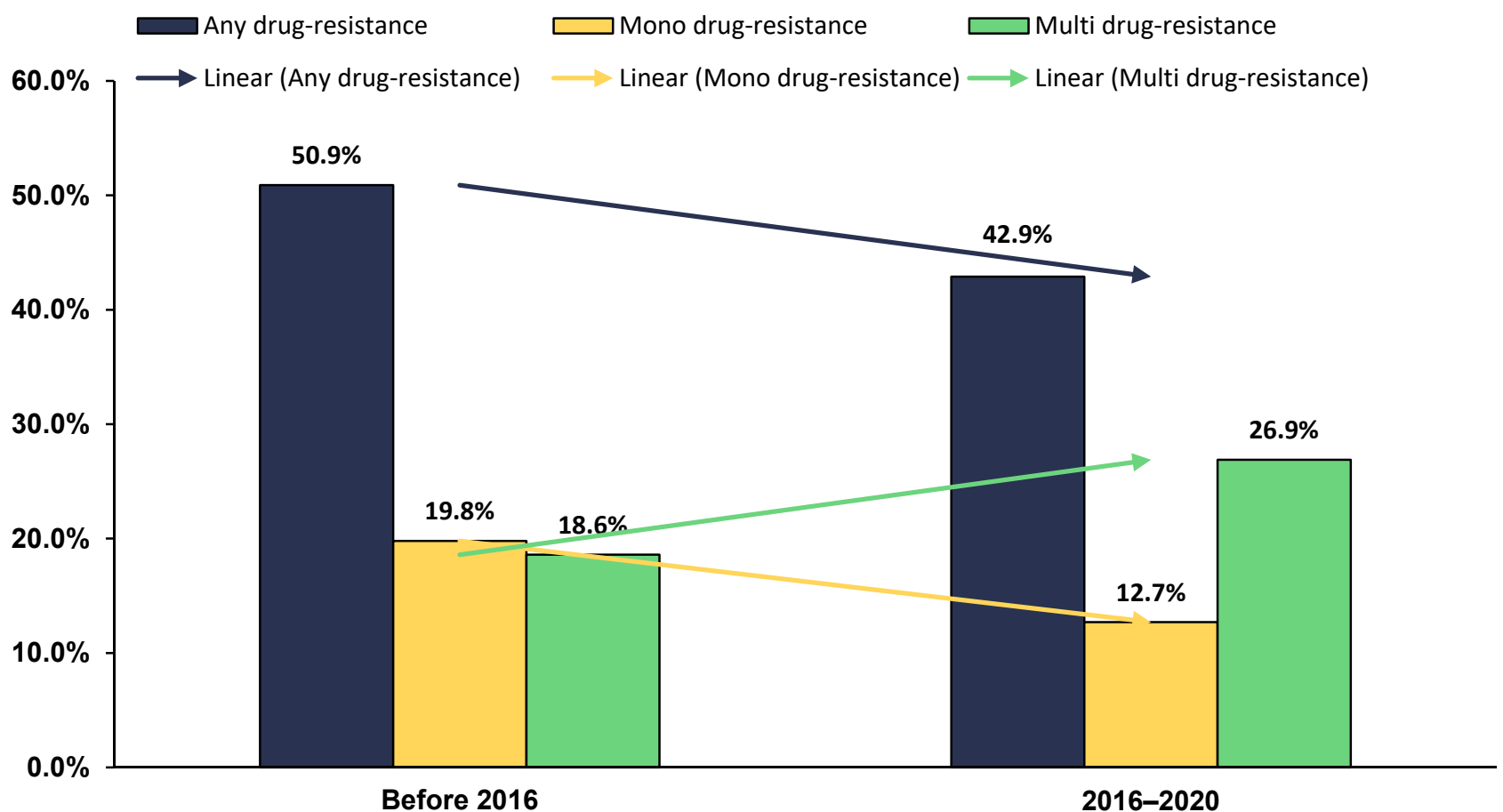

Figure 4. Anti-tuberculosis antibiotic resistance patterns in Sudan.

Table 4. Sensitivity analyses.

\begin{tabular}{|c|c|c|c|c|c|c|}
\hline \multirow{2}{*}{$\begin{array}{c}\text { Strategies of Sensitivity } \\
\text { Analyses }\end{array}$} & \multirow{2}{*}{$\begin{array}{c}\text { Prevalence of } \\
\text { Antibiotic Resistance } \\
{[95 \% \text { CIs] (\%) }}\end{array}$} & \multirow{2}{*}{$\begin{array}{l}\text { Difference of Pooled } \\
\text { Prevalence } \\
\text { Compared to the } \\
\text { Main Result }\end{array}$} & \multirow{2}{*}{$\begin{array}{l}\text { Number of } \\
\text { Studies } \\
\text { Analysed }\end{array}$} & \multirow{2}{*}{$\begin{array}{c}\text { Total } \\
\text { Number of } \\
\text { TB } \\
\text { Patients }\end{array}$} & \multicolumn{2}{|c|}{ Heterogeneity } \\
\hline & & & & & $I^{2}$ & $p$-Value \\
\hline \multicolumn{7}{|c|}{ Any drug resistance } \\
\hline $\begin{array}{l}\text { Excluding small studies } \\
\qquad(n<100)\end{array}$ & $41.2[27.3-55.1]$ & $6.3 \%$ lower & 8 & 1377 & $97 \%$ & $<0.0001$ \\
\hline $\begin{array}{l}\text { Excluding low- and } \\
\text { moderate-quality studies }\end{array}$ & $44.9[31.6-58.1]$ & $2.6 \%$ lower & 8 & 1127 & $96 \%$ & $<0.0001$ \\
\hline Using a fixed-effects model & $42.4[40.2-44.6]$ & $5.1 \%$ lower & 13 & 1666 & $96 \%$ & $<0.0001$ \\
\hline \multicolumn{7}{|c|}{ Mono drug resistance } \\
\hline $\begin{array}{l}\text { Excluding small studies } \\
\qquad(n<100)\end{array}$ & $12.7[3.5-21.9]$ & $4.8 \%$ lower & 4 & 667 & $93 \%$ & $<0.0001$ \\
\hline $\begin{array}{l}\text { Excluding low- and } \\
\text { moderate-quality studies }\end{array}$ & $14.0[6.4-21.6]$ & $3.5 \%$ lower & 6 & 783 & $91 \%$ & $<0.0001$ \\
\hline Using a fixed-effects model & $6.6[5.0-8.1]$ & $10.9 \%$ lower & 8 & 903 & $90 \%$ & $<0.0001$ \\
\hline \multicolumn{7}{|c|}{ Multidrug resistance } \\
\hline $\begin{array}{l}\text { Excluding small studies } \\
\qquad(n<100)\end{array}$ & $19.2[10.7-27.7]$ & $3.0 \%$ lower & 8 & 1377 & $95 \%$ & $<0.0001$ \\
\hline $\begin{array}{l}\text { Excluding low- and } \\
\text { moderate-quality studies }\end{array}$ & $27.6[17.9-37.2]$ & $4.8 \%$ higher & 10 & 1247 & $95 \%$ & $<0.0001$ \\
\hline Using a fixed-effects model & 15.7 [14.1-17.3] & $7.1 \%$ lower & 15 & 1786 & $94 \%$ & $<0.0001$ \\
\hline
\end{tabular}


Table 4. Cont.

\begin{tabular}{|c|c|c|c|c|c|c|}
\hline \multirow{2}{*}{$\begin{array}{c}\text { Strategies of Sensitivity } \\
\text { Analyses }\end{array}$} & \multirow{2}{*}{$\begin{array}{c}\text { Prevalence of } \\
\text { Antibiotic Resistance } \\
{[95 \% \text { CIs] }(\%)}\end{array}$} & \multirow{2}{*}{$\begin{array}{c}\text { Difference of Pooled } \\
\text { Prevalence } \\
\text { Compared to the } \\
\text { Main Result }\end{array}$} & \multirow{2}{*}{$\begin{array}{l}\text { Number of } \\
\text { Studies } \\
\text { Analysed }\end{array}$} & \multirow{2}{*}{$\begin{array}{c}\text { Total } \\
\text { Number of } \\
\text { TB } \\
\text { Patients } \\
\end{array}$} & \multicolumn{2}{|c|}{ Heterogeneity } \\
\hline & & & & & $I^{2}$ & $p$-Value \\
\hline \multicolumn{7}{|c|}{ Poly drug resistance } \\
\hline $\begin{array}{l}\text { Excluding small studies } \\
\qquad(n<100)\end{array}$ & $6.4[2.3-10.4]$ & $0.4 \%$ lower & 1 & 141 & NA & NA \\
\hline $\begin{array}{l}\text { Excluding low- and } \\
\text { moderate-quality studies }\end{array}$ & $3.9[0.0-8.5]$ & $2.9 \%$ lower & 2 & 201 & $69 \%$ & 0.70 \\
\hline Using a fixed-effects model & $4.5[2.1-6.9]$ & $2.3 \%$ lower & 3 & 271 & $81 \%$ & 0.005 \\
\hline \multicolumn{7}{|c|}{ Extensive drug resistance } \\
\hline $\begin{array}{l}\text { Excluding small studies } \\
\qquad(n<100)\end{array}$ & $0.7[0.0-2.1]$ & No change & 1 & 141 & NA & NA \\
\hline $\begin{array}{l}\text { Excluding low- and } \\
\text { moderate-quality studies }\end{array}$ & $0.7[0.0-2.1]$ & No change & 1 & 141 & NA & NA \\
\hline Using a fixed-effects model & $0.7[0.0-2.1]$ & No change & 1 & 141 & NA & NA \\
\hline
\end{tabular}

CIs: confidence intervals, NA: not applicable.

\section{Discussion}

Availability of comprehensive data on the prevalence and patterns of DR-TB in endemic areas are extremely essential for designing targeted strategies. To the best of our knowledge, this SRMA is the first to address the prevalence of drug-resistant TB in Sudan. It is worth mentioning that the estimation of DR-TB presented by the TB control programs in Sudan are based on systematic sampling from TB treatment centres or potentially endemic settings using a standardised drug susceptibility test. In contrast, the findings of this SRMA were generated by pooling eligible data on the prevalence of DR-TB reported in 16 published studies. As expected, outcomes were heterogeneous, which was most likely due to the methodological variations between the included studies, sample size and settings. Therefore, the calculated estimates might be confounded by the aforementioned factors and might not truly represent the TB-resistant population in Sudan; nonetheless, it is a first step in raising awareness about Sudan's potentially alarming TB drug-resistant situation.

The pooled estimate revealed that $47.0 \%$ of all TB cases, $30.7 \%$ of new cases and $62.8 \%$ of previously treated cases from different parts of Sudan had resistance to at least one antibiotic. This suggests that the country may have a high rate of DR-TB, which will likely spread to communities if not appropriately contained. The overall prevalence of any anti-TB-DR (47.0\%) identified in the current study was consistent with the finding of similar comprehensive estimates from Bangladesh (resistance to any drug $=45.3 \%$ ) [31]. However, it was higher than the resistance reported in India (40\%) [32] and China (31.1\%) [33]. In general, differences in resistance rates among countries might be attributed to the variations in baseline resistance, population density, nature of study participants and many other factors. Of note, the proportion of the overall drug resistance in this study was higher probably because the majority of the included studies were conducted in TB treatment clinics where patients were more likely to have resistant strains. Therefore, the calculated estimates might not accurately represent the Sudanese TB-resistant population. Furthermore, TB patients were recruited from Khartoum in 11 of the 16 included studies, despite the fact that the patients were referred from different regional hospitals. This prevented the synthesis of DR-TB pattern based on the country regions. This raises further concerns about the exact status of the regional prevalence of DR-TB.

According to the literature, the history of previous treatments is one of the most important risk factors associated with DR-TB [34,35]. Previously treated TB patients are more likely to harbour DR-TB strains than new cases [36]. Consistently, this finding was also evidenced by the results of this SRMA, which indicated that almost two-thirds (62.8\%) 
of TB patients with treatment history were resistant to at least one anti-TB drugs compared with only $30.7 \%$ of new cases. This observation was similar to the prevalence reported in previously treated patients from Iran (65.6\%) [37] and India (58.4\%) [38]. Among new cases, the pooled prevalence of any resistance was comparable with the estimate of a previous meta-analysis by Onyedum et al. [39], who found that $32.0 \%$ of new TB cases were resistant to at least one drug. In contrast, some studies have reported a lower number of drugresistant cases among newly diagnosed patients from China $(20.1 \%)$ and Iran $(23 \%)[37,40]$.

Concerning the first-line drugs, the standardised regimen for anti-TB treatment includes five essential antibiotics: isoniazid, rifampicin, pyrazinamide, ethambutol and streptomycin, according to the Sudan national TB management guideline, 2018 [41]. New and re-treatment TB patients typically receive a standard first-line treatment regimen that consists of two months of isoniazid, rifampicin, pyrazinamide and ethambutol (fixed-dose combinations), followed by four months of isoniazid and rifampicin. In general, high rates of resistance to isoniazid, streptomycin and rifampicin are unfortunate realities in the majority of TB-endemic countries. Such high rates could reflect the frequent, unjustified and inadequate use of antibiotics in general care. In Sudan, the current study revealed that resistance to isoniazid (32.3\%) and streptomycin $(31.7 \%)$ was the most prominent among all patients with TB. Similarly, in many other studies conducted in Bangladesh, Iran and China, resistance to these antibiotics is more common than resistance to other first-line drugs $[31,37,42]$. Although the resistance to isoniazid among the previously treated patients (42.8\%) and newly diagnosed patients (15.7\%) was high in the current study, it is still less than that reported from India $(38.8 \%$ in new cases and $79.5 \%$ in previously treated patients) [43]. Regardless of the high rate of isoniazid resistance in many parts of the world, isoniazid remains one of the most effective anti-TB drugs. However, the high resistance rate in this study should not be neglected because isoniazid-resistant precursors might accumulate in the country endemic settings. Consequently, the likelihood of developing MDR-TB could significantly increase if rifampicin resistance increased. Unfortunately, resistance to any rifampicin in the present study was also high among all TB cases $(29.2 \%)$ and in previously treated patients (39.3\%). By contrast, the prevalence was low in new cases (14.8\%). This finding is consistent with the SRMA reported in Bangladesh [31], but it is higher than that obtained in studies in Ethiopia and Rwanda [38,44]. The high rate of rifampicin resistance among previously treated patients in this study necessitates implementing an improved monitoring system for all patients undergoing treatment to limit the emergence of more drug-resistant strains.

The overall estimated mono-resistance rate in Sudan was $16.2 \%$, which was higher than the prevalence (14.3\%) reported from Bangladesh [31]. The results of this study showed that the rate of mono-resistant isolates among new TB cases was $21.2 \%$, which was higher than that in Iran (17.1\%) [37] and in China (10.8\%) [40]. Conversely, the prevalence of mono-resistance TB in previously treated patients $(18.8 \%)$ was close to the prevalence reported in Nigeria (17.0\%) [39] but higher than that in Iran (22.0\%) [37].

Although rifampicin and isoniazid are major components of antibiotic regimens used in the treatment of $\mathrm{TB}$, the high resistance burden of both drugs has resulted in a relatively high resistance rate of MDR. In Sudan, MDR-TB has not been sufficiently addressed because of the lack of adequate resources for control efforts. Based on this meta-analysis, the MDR-TB prevalence was estimated to be $11.4 \%$ in newly diagnosed patients and $41.5 \%$ of previously treated patients, with an overall prevalence of $22.8 \%$. This finding is remarkably higher than that of a previous meta-analysis [45], which revealed that $21.07 \%$ of the previously treated patients in Ethiopia have MDR-TB. Likewise, the rates of MDR-TB in new and previously treated patients in Sudan are higher than those documented in other studies conducted in Nigeria [39], Ethiopia [46], sub-Saharan Africa [47] and China $[40,48]$. Consistent with various previous reports, our findings further confirmed the high association of MDR-TB with the history of previous TB treatment.

Nevertheless, an inadequate treatment with insufficient duration and TB infection relapse may significantly contribute to the high prevalence of MDR-TB [49]. Furthermore, 
several anthropogenic factors, such as poor prescribing practices among medical doctors and poor drug selection, are also associated with acquired resistant TB. It is known that when first-line drugs fail in the treatment of patients with MDR-TB, second-line anti-TB drugs should be used, but they are more toxic, less effective and more expensive than first-line drugs. Thus far, only a few studies have reported the resistance to second-line drugs in Sudan. In the present study, resistance was only observed in ofloxacin $(2.1 \%)$, kanamycin $(0.7 \%)$ and para-aminosalicylic acid $(22.7 \%)$. The resistance frequency of the injectable second-line drug kanamycin was lower than that found in Zimbabwe (5\%) [50] and China (16.7\%) [51]. Similarly, the low resistance rate to ofloxacin in this study was consistent with the previous finding from Georgia in which resistance to ofloxacin was found to be $2.2 \%$; however, resistance to kanamycin in Georgia was slightly high compared to this study [52].

With the improper usage of second-line drugs, XDR-TB has developed and subsequently emerged. These strains are highly resistant and often associated with high morbidity, treatment failure and mortality. Thus, the growing trend of resistance to secondline anti-TB drugs and XDR-TB is alarming. Fortunately, this meta-analysis captured only one study in Sudan reporting a very low proportion of XDR-TB (0.7\%). A similar rate of XDR-TB was reported in Pakistan [53]. However, the findings of one study may not provide sufficient detailed information and should be confirmed with additional testing of TB isolates. Therefore, further studies should also be performed to explore the burden of XDR-TB in Sudan.

The prevalence of DR-TB in Sudan over an 18-year period revealed clear evidence of a declining trend in any drug-resistant TB. This finding is inconsistent with the remarkable increase in any drug-resistant TB, which was recently documented in Bangladesh between 2011 and 2018, when compared to 1999 and 2010 [31]. On the other hand, the prevalence of MDR-TB was found to be higher (26.9\%) in the most recent studies (2016-2020), as compared to $18.6 \%$ for studies conducted before 2016. Such an increasing trend has been similarly reported in various recent studies conducted in Bangladesh [31] and India [32]. On the other hand, a declining trend in the MDR-TB prevalence was observed sub-Saharan Africa during the period between 1995 and 2015 [47]. Perhaps the increasing trend of MDR-TB reported in this SRMA may not necessarily reflect the situation of MDR-TB on a national scale, but it does partially reveal some defects in the current TB control program.

As a direct implication of this study for TB control in Sudan, several influencing factors for the development of DR-TB and MDR-TB in Sudan should be considered immediately in order to prevent the accelerating spread of DR-TB. First, the key issue that must be addressed is the DR-TB detection system [54], given that the National Reference TB Laboratory in Khartoum is the only reference laboratory in the country [55]. The establishment of a rapid identification system and the strengthening of the capacity of TB reference and zonal laboratories would allow for the proper detection, treatment and management of drug-susceptible TB, thereby preventing the development of DR-TB [56].

Second, implementing effective control measures in TB treatment clinics and hospitals has a high potential for protecting both other patients and healthcare workers. In this regard, control measures consisting of administrative, environmental and personal respiratory protective equipment usage would be an adequate health system response. On the other hand, creative strategies to limit transmission inside community hotspots must be considered [57]. At the community level, it is important to screen household contacts, symptomatic individuals and high-risk groups, particularly children and immunocompromised patients, followed by a supervised treatment, which plan may play a crucial role in reducing the risk of transmission [56]. Furthermore, engaging the entire healthcare system in TB-related activities is also important, besides empowering individuals and communities to support a TB control plan and reduce TB-related stigma [58].

Third, the rational use of anti-TB drugs has been a problem in developing countries; thus, the availability of therapeutic procedures within the framework of internationally 
recognised standardised treatment regimens, particularly those recommended by the WHO, might be the basis of preventing and containing the further spread of DR-TB $[59,60]$.

Finally, it is clear that the majority of the studies included in this review were limited by cost and accessibility of collecting samples from endemic areas rather than TB treatment clinics. Despite the alarming results, in most of the included studies DR-TB rates were obtained from a smaller sample size. Therefore, expanded surveillance as well as additional studies with a large and systematic sample collection covering various geographical regions across the country are highly recommended [61].

A key strength of this SRMA is that it is the first to provide a comprehensive estimation of drug-resistant TB in Sudan. However, it had several limitations. First, the included studies did not encompass all the states of the country, so the estimated prevalence might not fully represent the magnitude of drug-resistant TB in Sudan. Second, substantial heterogeneity was observed in the included studies, although this observation is common in meta-analyses on estimating prevalence [62-64]. Third, all of the included studies were hospital-based studies and none were community-based studies, making the results more susceptible to potential selection bias. Finally, the potential effect of gender, age, socioeconomic status and lifestyle of the included patients on the prevalence of DR-TB could not be analysed because of the unavailability of data in many of the included studies.

\section{Methods}

\subsection{Reporting Guideline and Protocol Registration}

This study was conducted in compliance with the guidelines of the updated Preferred Reporting Items for Systematic Reviews and Meta-analyses (PRISMA) [65]. The protocol of this study was registered on the International Prospective Register of Systematic Reviews (PROSPERO) database (registration number: CRD42021249885).

\subsection{Search Strategies}

A comprehensive literature search was conducted to find studies on DR-TB prevalence in Sudan that were available in the PubMed, Scopus, Web of Science and Google Scholar databases. In addition, the reference lists of the included articles were also checked for the identification of studies that we missed through the search strategies. The detailed search strategy for all databases is presented in Table S2.

\subsection{Selection Criteria}

Studies that reported or provided adequate data for calculating the prevalence of antibiotic resistance in all, newly and/or previously treated TB patients from Sudan, regardless of age, gender or language restrictions, and regardless of the period in which the studies were conducted or published, were considered eligible for inclusion in this SRMA. By contrast, studies that reported extrapulmonary TB or considered only TB cases co-infected with HIV infection, thesis, review articles, case reports, case studies and studies with abstracts only were excluded.

\subsection{Data Management and Study Selection}

All identified studies were retrieved and managed using EndNote (Clarivate Analytics, Boston, MA, USA). Duplicates were removed, and the remaining papers were evaluated extensively based on their titles and abstracts. Full texts were further assessed for the identification of eligible studies. Two authors (K.H. and M.M.) independently evaluated the studies' eligibility using predetermined criteria. Discrepancies were resolved by discussing with the third author (M.A.I.) until a consensus was reached. 


\subsection{Operational Definitions}

The following definitions were adopted in compliance with the DR-TB guidelines that were used in this meta-analysis [66]. First-line drugs: rifampicin, isoniazid ethambutol, pyrazinamide and streptomycin. Second-line drugs: ofloxacin, moxifloxacin, levofloxacin, ciprofloxacin, kanamycin, capreomycin, amikacin, ethionamide, prothionamide, cycloserine and para-aminosalicylic acid. Mono resistance: resistance to only one first-line anti-TB drug. Poly resistance: other than isoniazid and rifampicin, resistance to more than one first-line anti-TB drug. Multidrug resistance (MDR): resistance to at least both isoniazid and rifampicin. Any drug resistance was defined as resistance to any drug regardless to mono resistance or MDR. Extensive drug resistance (XDR): multidrug resistance, fluoroquinolone resistance and resistance to at least one of the three second-line injectable drugs.

\subsection{Data Extrction}

Two reviewers (K.H. and M.M.) independently extracted relevant data or information from the included studies using a standardised data extraction form. To minimise errors and ensure consistency, a third author (M.I.I.) subsequently double-checked the extracted data or information. From each eligible study, the following data were extracted: last name of the first author, year of publication, study design, study enrolment time, region/province, distributions of gender and age in the study population, number of TB-positive patients, drug susceptibility test (DST) and the prevalence of drug resistance (any, mono, multi and poly resistant).

\subsection{Quality Assessment}

The quality of the included studies was independently evaluated by two of the authors (K.H. and M.A.I.) using the Joana Brigg's Institute (JBI) critical assessment checklist for cross-sectional studies [67]. The results of the two authors' assessment were then compared, and notable discrepancies were identified. Consequently, any disagreement was resolved by consensus. Studies with scores of $>70 \%$ reporting 'yes' were considered to have a low risk of bias (high quality). Studies with scores of $50 \%-70 \%$ were considered to have a moderate risk of bias (moderate quality). Finally, studies with scores of $<50 \%$ reporting 'yes' were considered to have a high risk of bias [68].

\subsection{Data Analyses}

Meta-analysis was carried out using metaprop codes in the meta (version 4.15-1) and metafor (version 2.4-0) packages of $R$ (version 3.6.3) in RStudio (version 1.3.1093). The pooled estimates of resistance to any drugs and mono resistance, MDR, poly resistance and XDR and 95\% confidence intervals (CIs) were calculated using the REML method for the random-effects models. Heterogeneity between studies was measured using $I^{2}$ statistics and Cochran's Q-test. The $I^{2}$ statistic of $>75 \%$ and a significance level of $<0.05$ were interpreted as evidence of substantial heterogeneity. The presence of publication bias was checked by visually inspecting the funnel plot tested for significance with Egger's test. However, the insufficient number of included studies (less than 10) rendered the use of the Funnel plot technique in assessing publication bias unnecessary.

\subsection{Subgroup and Sensitivity Analyses}

For exploring the potential sources of heterogeneity, a subgroup analysis of DR-TB prevalence was carried out according to specific first- and second-line drugs and resistance patterns in new cases and previously treated cases. The robustness of the pooled estimates was validated through sensitivity analysis, which was conducted according to the following strategies: exclusion of small studies $(n<100)$, exclusion of low- and moderate-quality studies and uses of a fixed-effects model. 


\section{Conclusions}

The pooled estimates demonstrated a relatively high burden of DR-TB in Sudan posing a new challenge to public health. Our results suggested that drug susceptibility test should be initiated and scaled up quickly in order to identify resistant strains rapidly. In addition, robust national surveillance systems should be established for the effective treatment, prevention and continuous monitoring of drug-resistant TB in Sudan.

Supplementary Materials: The following are available online at https:/ / www.mdpi.com/article/ 10.3390/antibiotics10080932/s1, Figure S1: Any resistance to first- and second-line anti-TB drugs: (A) streptomycin, (B) isoniazid, (C) rifampicin, (D) ethambutol, (E) pyrazinamide, (F) kanamycin, (G) ofloxacin and (H) para-aminosalicylic acid, Figure S2: Mono resistance to anti-TB drugs: (A) streptomycin, (B) isoniazid, (C) rifampicin and (D) ethambutol, Figure S3: Any resistance to anti-TB drugs in newly diagnosed patients: (A) streptomycin (B) isoniazid, (C) rifampicin, (D) ethambutol and (E) pyrazinamide, and any resistance to anti-TB drugs in previously treated patients: (F) streptomycin, $(\mathrm{G})$ isoniazid, $(\mathrm{H})$ rifampicin, (I) kanamycin, $(\mathrm{J})$ ofloxacin and $(\mathrm{K})$ pyrazinamide, Figure S4: Mono resistance to anti-TB drugs in newly diagnosed patients: (A) streptomycin, (B) isoniazid, (C) rifampicin and (D) ethambutol, and mono resistance to anti-TB drugs in previously treated patients: (E) streptomycin, $(\mathrm{F})$ isoniazid, $(\mathrm{G})$ rifampicin and $(\mathrm{H})$ ethambutol, Figure S5: Overall drug resistance (DR) in newly diagnosed and previously treated TB patients. (A) Any DR in newly diagnosed patients, (B) any DR in previously treated patients, (C) mono DR in newly diagnosed patients, (D) mono DR in previously treated patients, (E) multi DR in newly diagnosed patients, (F) multi DR in previously treated patients, $(G)$ poly DR in newly diagnosed patients and $(\mathrm{H})$ poly DR in previously treated patients, Figure S6: Sensitivity analyses: excluding small studies $(n<100)$ from A to E; excluding moderate-quality studies from F to J and using a fixed-effects model from K to O, Table S1: Quality assessment of the included cross-sectional studies, Table S2: Search strategy.

Author Contributions: Conceptualisation, K.H. and M.A.I.; methodology, K.H., M.I.I. and M.A.I.; software, M.A.I.; validation, M.A.I. and M.M.; formal analysis, M.A.I.; investigation, K.H., M.M., M.I.I. and M.A.I.; resources, M.A.I. and K.H.; data curation, M.M. and M.I.I.; writing-original draft preparation, K.H.; writing-review and editing, M.M., M.I.I. and M.A.I.; visualisation, M.A.I. and M.M.; supervision, M.A.I. and K.H.; project administration, M.A.I. and K.H.; funding acquisition, M.A.I. All authors have read and agreed to the published version of the manuscript.

Funding: The APC was funded by the Research Creativity and Management (RCMO), Universiti Sains Malaysia (USM) and the School of Medical Sciences, USM.

Institutional Review Board Statement: Not applicable.

Informed Consent Statement: Not applicable.

Data Availability Statement: The data presented in this study are available within the article and Supplementary Materials.

Conflicts of Interest: The authors declare no conflict of interest.

\section{References}

1. World Health Organization. Global Tuberculosis Report. 2019. Available online: https://apps.who.int/iris/bitstream/handle/10 665/329368/9789241565714-eng.pdf (accessed on 1 June 2021).

2. Simmons, J.D.; Stein, C.M.; Seshadri, C.; Campo, M.; Alter, G.; Fortune, S.; Schurr, E.; Wallis, R.S.; Churchyard, G.; Mayanja-Kizza, H.; et al. Immunological mechanisms of human resistance to persistent Mycobacterium tuberculosis infection. Nat. Rev. Immunol. 2018, 18, 575-589. [CrossRef] [PubMed]

3. World Health Organization. Global Tuberculosis Report. 2020. Available online: https://apps.who.int/iris/bitstream/handle/10 665/336069/9789240013131-eng.pdf (accessed on 1 June 2021).

4. Trauer, J.M.; Dodd, P.J.; Gomes, M.G.M.; Gomez, G.B.; Houben, R.M.; McBryde, E.S.; Melsew, Y.A.; Menzies, N.A.; Arinaminpathy, N.; Shrestha, S. The importance of heterogeneity to the epidemiology of tuberculosis. Clin. Infect. Dis. 2019, 69, 159-166. [CrossRef]

5. Lönnroth, K.; Jaramillo, E.; Williams, B.G.; Dye, C.; Raviglione, M. Drivers of tuberculosis epidemics: The role of risk factors and social determinants. Soc. Sci. Med. 2009, 68, 2240-2246. [CrossRef]

6. Adebisi, Y.A.; Agumage, I.; Sylvanus, T.D.; Nawaila, I.J.; Ekwere, W.A.; Nasiru, M.; Okon, E.E.; Ekpenyong, A.M.; Lucero-Prisno III, D.E. Burden of tuberculosis and challenges facing its eradication in West Africa. Int. J. Infect. 2019, 6, e92250. [CrossRef] 
7. World Health Organization. Rapid Communication: Key Changes to Treatment of Multidrug- and Rifampicin-Resistant Tuberculosis (MDR/RR-TB). 2018. Available online: https:/ / apps.who.int/iris/handle/10665/275383 (accessed on 1 June 2021).

8. Faustini, A.; Hall, A.J.; Perucci, C.A. Risk factors for multidrug resistant tuberculosis in Europe: A systematic review. Thorax 2006, 61, 158-163. [CrossRef]

9. Saravanan, M.; Niguse, S.; Abdulkader, M.; Tsegay, E.; Hailekiros, H.; Gebrekidan, A.; Araya, T.; Pugazhendhi, A. Review on emergence of drug-resistant tuberculosis (MDR \& XDR-TB) and its molecular diagnosis in Ethiopia. Microb. Pathog. 2018, 117, 237-242.

10. Jassal, M.; Bishai, W.R. Extensively drug-resistant tuberculosis. Lancet Infect. Dis. 2009, 9, 19-30. [CrossRef]

11. Dookie, N.; Rambaran, S.; Padayatchi, N.; Mahomed, S.; Naidoo, K. Evolution of drug resistance in Mycobacterium tuberculosis: A review on the molecular determinants of resistance and implications for personalized care. J. Antimicrob. Chemother. 2018, 73, 1138-1151. [CrossRef]

12. World Health Organization. Guidance for the Surveillance of Drug Resistance in Tuberculosis: Sixth Edition. 2020. Available online: https: / www.who.int/publications/i/item/9789240018020 (accessed on 1 June 2021).

13. Chisompola, N.K.; Streicher, E.M.; Muchemwa, C.M.K.; Warren, R.M.; Sampson, S.L. Molecular epidemiology of drug resistant Mycobacterium tuberculosis in Africa: A systematic review. BMC Infect. Dis. 2020, 20, 1-16. [CrossRef]

14. Ismail, N.; Omar, S.V.; Ismail, F.; Blows, L.; Koornhof, H.; Onyebujoh, P.C.; Gardee, Y. Drug resistant tuberculosis in Africa: Current status, gaps and opportunities. Afr. J. Lab. Med. 2018, 7, 1-11. [CrossRef]

15. Abdul-Aziz, A.A.; Elhassan, M.M.; Abdulsalam, S.A.; Mohammed, E.O.; Hamid, M.E. Multi-drug resistance tuberculosis (MDR-TB) in Kassala state, eastern Sudan. Trop. Dr. 2013, 43, 66-70. [CrossRef]

16. Adam, M.A.M.; Ali, H.M.H.; Khalil, E.A.G. First-line drug resistance patterns of Mycobacterium tuberculosis complex isolates from re-treatment patients from Sudan. J. Tuberc. Res. 2016, 4, 98-104. [CrossRef]

17. Adam, M.A.M.; Ali, H.M.H.; Khalil, E.A.G. Initial second-line drug resistance of Mycobacterium tuberculosis isolates from Sudanese retreatment-patients. J. Clin. Tuberc. Other Mycobact. Dis. 2017, 9, 21-23. [CrossRef]

18. Ali, R.H.; Ibrahim, N.Y.; Elegail, A.M.A.; Eltohami, N.A.M.; Ebraheem, R.S.M.; Ahmed, S.F.M.; Ahmed, H.H.H.; Nour, E.O.M.; Eldirdery, M.M.; Musa, H.H. Evaluation of GeneXpert MTB/RIF and line probe assay for rapid diagnosis of Mycobacterium tuberculosis in Sudanese pulmonary TB patients. Asian Pac. J. Trop. Dis. 2017, 15, 426-429. [CrossRef]

19. Eldirdery, M.M.; Elrayah, I.E.; Elkarim, M.; Khalid, F.A.; Ma, A.; Elegail, S.; Ibrahim, N.Y.; Nour, E.O.M.; Ali, R.H.; Hamdan, H.M.; et al. Rapid detection of multi drug resistant-tuberculosis using Line Probe Assay (LPA) in Sudan. Eur. Acad. Res. 2016, 3, 10755-10768.

20. Eldirdery, M.M.; Intisar, E.; Mona, O.; Fatima, A.; Asrar, M.; Nuha, Y. Prevalence of multidrug-resistant tuberculosis among smear positive pulmonary tuberculosis patients in eastern Sudan. Am. J. Microbiol. Res. 2017, 5, 32-36.

21. Elhassan, M.M.; Saeed, S.M.; Elmekki, M.A.; Al Jarie, A.A.; Hamid, M.E. Detection of multidrug-resistant tuberculosis using PCR compared to the conventional proportional method. Bahrain Med. Bull. 2012, 34, 11-14.

22. Farah Aldour, M.S.M.; Elhussein, A.R.M.; Elkhidir, I.M.; Tayeib, S.E.; Mohammed Khair, O.; Mohamed, N.S.; Enan, K.A. Detection of Drug Resistant Genes of Mycobacterium tuberculosis in Sudanese Tuberculosis Patients in Khartoum State Using Multiplex PCR. EC Microbiol. 2018, 14, 686-693.

23. Hassan, S.; Musa, M.; Elsheikh, H.; Eleragi, A.; Saeed, N. Drug resistance in Mycobacterium tuberculosis isolates from northeastern Sudan. J. Adv. Med. Med. Res. 2012, 2, 424-433. [CrossRef]

24. Khalid, F.A.; Hamid, Z.A.; Mukhtar, M. Tuberculosis drug resistance isolates from pulmonary tuberculosis patients, Kassala State, Sudan. Int. J. Mycobacteriol. 2015, 4, 44-47. [CrossRef] [PubMed]

25. Nour, E.M.; Saeed, E.M.; Zaki, A.; Saeed, N.S. Drug resistance patterns of Mycobacterium tuberculosis isolates from patients with pulmonary tuberculosis in the Sudan. IOSR J. Dent. Med. Sci. 2015, 14, 17-19.

26. Sabeel, S.; Salih, M.A.; Ali, M.; El-Zaki, S.-E.; Abuzeid, N.; Elgadi, Z.A.M.; Altayb, H.N.; Elegail, A.; Ibrahim, N.Y.; Elamin, B.K. Phenotypic and genotypic analysis of multidrug-resistant Mycobacterium tuberculosis isolates from Sudanese patients. Tuberc. Res. Treat. 2017, 2017, 1-6.

27. Sharaf-Eldin, G.; Saeed, N.; Hamid, M.; Jordaan, A.; Van der Spuy, G.; Warren, R.; Van Helden, P.; Victor, T. Molecular analysis of clinical isolates of Mycobacterium tuberculosis collected from patients with persistent disease in the Khartoum region of Sudan. J. Infect. 2002, 44, 244-251. [CrossRef]

28. Eldin, G.S.S.; Fadl-Elmula, I.; Ali, M.S.; Ali, A.B.; Salih, A.L.G.; Mallard, K.; Bottomley, C.; McNerney, R. Tuberculosis in Sudan: A study of Mycobacterium tuberculosis strain genotype and susceptibility to anti-tuberculosis drugs. BMC Infect. Dis. 2011, 11, 1-8.

29. Shuaib, Y.A.; Khalil, E.A.; Wieler, L.H.; Schaible, U.E.; Bakheit, M.A.; Mohamed-Noor, S.E.; Abdalla, M.A.; Kerubo, G.; Andres, S.; Hillemann, D. Mycobacterium tuberculosis Complex Lineage 3 as Causative Agent of Pulmonary Tuberculosis, Eastern Sudan. Emerg. Infect. Dis. 2020, 26, 427-436. [CrossRef]

30. Zaki, A.; Ibrahim, N.; Abdelsalam, A.; Osman, M. A study on Prevalence of Drug Resistance in Drug Default Pulmonary Tuberculosis. Sudan J. Med. Sci. 2011, 6, 97-101. [CrossRef]

31. Kundu, S.; Marzan, M.; Gan, S.H.; Islam, M.A. Prevalence of Antibiotic-Resistant Pulmonary Tuberculosis in Bangladesh: A Systematic Review and Meta-Analysis. Antibiotics 2020, 9, 710. [CrossRef]

32. Goyal, V.; Kadam, V.; Narang, P.; Singh, V. Prevalence of drug-resistant pulmonary tuberculosis in India: Systematic review and meta-analysis. BMC Public Health 2017, 17, 817. [CrossRef] 
33. Lv, X.-T.; Lu, X.-W.; Shi, X.-Y.; Zhou, L. Prevalence and risk factors of multi-drug resistant tuberculosis in Dalian, China. J. Int. Med. Res. 2017, 45, 1779-1786. [CrossRef]

34. Saifullah, A.; Mallhi, T.H.; Khan, Y.H.; Iqbal, M.S.; Alotaibi, N.H.; Alzarea, A.I.; Rasheed, M. Evaluation of risk factors associated with the development of MDR-and XDR-TB in a tertiary care hospital: A retrospective cohort study. PeerJ 2021, 9, e10826. [CrossRef]

35. Balaji, V.; Daley, P.; Anand, A.A.; Sudarsanam, T.; Michael, J.S.; Sahni, R.D.; Chordia, P.; George, I.A.; Thomas, K.; Ganesh, A. Risk factors for MDR and XDR-TB in a tertiary referral hospital in India. PLoS ONE 2010, 5, e9527. [CrossRef] [PubMed]

36. Workicho, A.; Kassahun, W.; Alemseged, F. Risk factors for multidrug-resistant tuberculosis among tuberculosis patients: A case-control study. Infect. Drug Resist. 2017, 10, 91-96. [CrossRef] [PubMed]

37. Nasiri, M.J.; Dabiri, H.; Darban-Sarokhalil, D.; Rezadehbashi, M.; Zamani, S. Prevalence of drug-resistant tuberculosis in Iran: Systematic review and meta-analysis. Am. J. Infect. Control 2014, 42, 1212-1218. [CrossRef] [PubMed]

38. Lohiya, A.; Abdulkader, R.S.; Rath, R.S.; Jacob, O.; Chinnakali, P.; Goel, A.D.; Agrawal, S. Prevalence and patterns of drug resistant pulmonary tuberculosis in India-A systematic review and meta-analysis. J. Glob. Antimicrob. Resist. 2020, 22, 308-316. [CrossRef]

39. Onyedum, C.C.; Alobu, I.; Ukwaja, K.N. Prevalence of drug-resistant tuberculosis in Nigeria: A systematic review and metaanalysis. PLoS ONE 2017, 12, e0180996. [CrossRef]

40. Duan, Q.; Chen, Z.; Chen, C.; Zhang, Z.; Lu, Z.; Yang, Y.; Zhang, L. The prevalence of drug-resistant tuberculosis in mainland China: An updated systematic review and meta-analysis. PLoS ONE 2016, 11, e0148041. [CrossRef]

41. Sudan National TB Manegement Guideline. 2018. Available online: https://www.humanitarianresponse.info/sites/www. humanitarianresponse.info/files/2019/07/Sudan-National-TB-management-Guideline-March.2019-1.pdf (accessed on 20 July 2021).

42. Yuen, C.M.; Tolman, A.W.; Cohen, T.; Parr, J.B.; Keshavjee, S.; Becerra, M.C. Isoniazid-resistant tuberculosis in children: A systematic review. Pediatr. Infect. Dis. J. 2013, 32, e217. [CrossRef]

43. Sinha, P.; Srivastava, G.; Gupta, A.; Anupurba, S. Association of risk factors and drug resistance pattern in tuberculosis patients in North India. J. Glob. Infect. Dis. 2017, 9, 139-145.

44. Umubyeyi, A.N.; Vandebriel, G.; Gasana, M.; Basinga, P.; Zawadi, J.P.; Gatabazi, J.; Pauwels, P.; Nzabintwali, F.; Nyiramasarabwe, L.; Fissette, K.; et al. Results of a national survey on drug resistance among pulmonary tuberculosis patients in Rwanda. Int. J. Tuberc. Lung Dis. 2007, 11, 189-194.

45. Girum, T.; Muktar, E.; Lentiro, K.; Wondiye, H.; Shewangizaw, M. Epidemiology of multidrug-resistant tuberculosis (MDR-TB) in Ethiopia: A systematic review and meta-analysis of the prevalence, determinants and treatment outcome. Trop. Dis. Travel Med. Vaccines 2018, 4, 1-12. [CrossRef]

46. Eshetie, S.; Gizachew, M.; Dagnew, M.; Kumera, G.; Woldie, H.; Ambaw, F.; Tessema, B.; Moges, F. Multidrug resistant tuberculosis in Ethiopian settings and its association with previous history of anti-tuberculosis treatment: A systematic review and metaanalysis. BMC Infect. Dis. 2017, 17, 219. [CrossRef]

47. Lukoye, D.; Ssengooba, W.; Musisi, K.; Kasule, G.W.; Cobelens, F.G.; Joloba, M.; Gomez, G.B. Variation and risk factors of drug resistant tuberculosis in sub-Saharan Africa: A systematic review and meta-analysis. BMC Public Health 2015, 15, 291. [CrossRef]

48. Ding, P.; Li, X.; Jia, Z.; Lu, Z. Multidrug-resistant tuberculosis (MDR-TB) disease burden in China: A systematic review and spatio-temporal analysis. BMC Infect. Dis. 2017, 17, 57. [CrossRef]

49. Liang, L.; Wu, Q.; Gao, L.; Hao, Y.; Liu, C.; Xie, Y.; Sun, H.; Yan, X.; Li, F.; Li, H.; et al. Factors contributing to the high prevalence of multidrug-resistant tuberculosis: A study from China. Thorax 2012, 67, 632-638. [CrossRef]

50. Sagonda, T.; Mupfumi, L.; Manzou, R.; Makamure, B.; Tshabalala, M.; Gwanzura, L.; Mason, P.; Mutetwa, R. Prevalence of extensively drug resistant tuberculosis among archived multidrug resistant tuberculosis isolates in Zimbabwe. Tuberc. Res. Treat. 2014, 2014, 349141. [CrossRef]

51. Hu, Y.; Xu, L.; He, Y.; Pang, Y.; Lu, N.; Liu, J.; Shen, J.; Zhu, D.; Feng, X.; Wang, Y. Prevalence and molecular characterization of second-line drugs resistance among multidrug-resistant Mycobacterium tuberculosis isolates in Southwest of China. Biomed Res. Int. 2017, 2017, 4563826. [CrossRef]

52. Jugheli, L.; Rigouts, L.; Shamputa, I.C.; Bram de Rijk, W.; Portaels, F. High levels of resistance to second-line anti-tuberculosis drugs among prisoners with pulmonary tuberculosis in Georgia. Int. J. Tuberc. Lung Dis. 2008, 12, 561-566.

53. Javaid, A.; Hasan, R.; Zafar, A.; Chaudry, M.; Qayyum, S.; Qadeer, E.; Shaheen, Z.; Agha, N.; Rizvi, N.; Afridi, M. Pattern of first-and second-line drug resistance among pulmonary tuberculosis retreatment cases in Pakistan. Int. J. Tuberc. Lung Dis. 2017, 21, 303-308. [CrossRef]

54. Koch, A.; Cox, H.; Mizrahi, V. Drug-resistant tuberculosis: Challenges and opportunities for diagnosis and treatment. Curr. Opin. Pharmacol. 2018, 42, 7-15. [CrossRef]

55. Ali, M.H.; Alrasheedy, A.A.; Hassali, M.A.; Kibuule, D.; Godman, B. Predictors of multidrug-resistant tuberculosis (MDR-TB) in Sudan. Antibiotics 2019, 8, 90. [CrossRef]

56. Fox, G.J.; Schaaf, H.; Mandalakas, A.; Chiappini, E.; Zumla, A.; Marais, B. Preventing the spread of multidrug-resistant tuberculosis and protecting contacts of infectious cases. Clin. Microbiol. Infect. 2017, 23, 147-153. [CrossRef] [PubMed]

57. Loddenkemper, R.; Sagebiel, D.; Brendel, A. Strategies against multidrug-resistant tuberculosis. Eur. Respir. J. 2002, 20, 66-77. [CrossRef] 
58. Mdivani, N.; Zangaladze, E.; Volkova, N.; Kourbatova, E.; Jibuti, T.; Shubladze, N.; Kutateladze, T.; Khechinashvili, G.; del Rio, C.; Salakaia, A. High prevalence of multidrug-resistant tuberculosis in Georgia. Int. J. Infect. Dis. 2008, 12, 635-644. [CrossRef] [PubMed]

59. Lange, C.; Chesov, D.; Heyckendorf, J.; Leung, C.C.; Udwadia, Z.; Dheda, K. Drug-resistant tuberculosis: An update on disease burden, diagnosis and treatment. Respirology 2018, 23, 656-673. [CrossRef] [PubMed]

60. Udwadia, Z.; Furin, J. Quality of drug-resistant tuberculosis care: Gaps and solutions. J. Clin. Tuberc. Other Mycobact. Dis. 2019, 16, 1-5. [CrossRef] [PubMed]

61. Ismail, N.A.; Mvusi, L.; Nanoo, A.; Dreyer, A.; Omar, S.V.; Babatunde, S.; Molebatsi, T.; Van der Walt, M.; Adelekan, A.; Deyde, V. Prevalence of drug-resistant tuberculosis and imputed burden in South Africa: A national and sub-national cross-sectional survey. Lancet Infect. Dis. 2018, 18, 779-787. [CrossRef]

62. Chia, Y.C.; Islam, M.A.; Hider, P.; Woon, P.Y.; Johan, M.F.; Hassan, R.; Ramli, M. The prevalence of TET2 gene mutations in patients with BCR-ABL-negative myeloproliferative neoplasms (MPN): A systematic review and meta-analysis. Cancers 2021, 13, 3078. [CrossRef]

63. Islam, M.A.; Kundu, S.; Alam, S.S.; Hossan, T.; Kamal, M.A.; Hassan, R. Prevalence and characteristics of fever in adult and paediatric patients with coronavirus disease 2019 (COVID-19): A systematic review and meta-analysis of 17515 patients. PLoS ONE 2021, 16, e0249788. [CrossRef] [PubMed]

64. Chang, C.-T.; Ang, J.-Y.; Islam, M.A.; Chan, H.-K.; Cheah, W.-K.; Gan, S.H. Prevalence of drug-related problems and complementary and alternative medicine use in Malaysia: A systematic review and meta-analysis of 37,249 older adults. Pharmaceuticals 2021, 14, 187. [CrossRef]

65. Page, M.J.; Moher, D.; Bossuyt, P.M.; Boutron, I.; Hoffmann, T.C.; Mulrow, C.D.; Shamseer, L.; Tetzlaff, J.M.; Akl, E.A.; Brennan, S.E. PRISMA 2020 explanation and elaboration: Updated guidance and exemplars for reporting systematic reviews. BMJ 2021, $372,1-36$.

66. World Health Organization. Definitions and Reporting Framework for Tuberculosis-2013 Revision: Updated December 2014 and January 2020. Available online: https://apps.who.int/iris/bitstream/handle/10665/79199/?sequence=1 (accessed on 20 July 2021).

67. Munn, Z.; Moola, S.; Lisy, K.; Riitano, D.; Tufanaru, C. Methodological guidance for systematic reviews of observational epidemiological studies reporting prevalence and cumulative incidence data. Int. J. Evid. Based Healthc. 2015, 13, 147-153. [CrossRef]

68. Islam, M.A.; Alam, S.S.; Kundu, S.; Hossan, T.; Kamal, M.A.; Cavestro, C. Prevalence of Headache in Patients With Coronavirus Disease 2019 (COVID-19): A Systematic Review and Meta-Analysis of 14,275 Patients. Front. Neurol. 2020, 11, 562634. [CrossRef] 